\title{
O conhecimento e o ensino sobre doenças sexualmente transmissíveis entre universitários
}

\author{
Awareness and education regarding sexually transmitted diseases \\ among undergraduate students
}

Eneida Lazzarini de Castro ${ }^{1}$
Tânia Alencar de Caldas ${ }^{2}$
André Moreno Morcillo ${ }^{3}$
Elisabete Monteiro de Aguiar Pereira ${ }^{2}$
Paulo Eduardo Neves Ferreira Velho ${ }^{4}$

${ }^{1}$ Departamento de Clínica Médica, Área de Ensino, Faculdade de Ciências Médicas (FCM), Universidade Estadual de Campinas (Unicamp). R. Tessália Vieira de Camargo 126, Cidade Universitária "Zeferino Vaz". 13083-887 Campinas SP Brasil. eneida_lazzarini@ yahoo.com.br ${ }^{2}$ Grupo de Estudos e Pesquisas em Educação Superior, Faculdade de Educação, Unicamp. Campinas SP Brasil.

${ }^{3}$ Departamento de Pediatria, FCM, Unicamp. Campinas SP Brasil. ${ }^{4}$ Departamento de Clínica Médica, FCM, Unicamp. Campinas SP Brasil.

\begin{abstract}
Sexually transmitted diseases (STDs) are the main global cause of acute illness and death and represent a high socioeconomic cost. Undergraduate students are highly exposed to STDs. The research developed at UNICAMP sought to quantify and generate self-perception of knowledge(or lack thereof) about STDs, as well as evaluate the interest of the students in a course on the topic. The data collection instrument was a questionnaire sent electronically to students about to graduate at the end of 2011 and to freshmen in 2012. The questionnaire was answered by 1,448 seniors and 371 freshmen. Twenty percent of seniors and $38 \%$ of freshmen had no sexual activity. Among sexually active students, $26.9 \%$ had no regular partner and $28.2 \%$ more than two partners per year. The condom was used by $99 \%$ of students, but less than 20\% used them appropriately. About $80 \%$ were unaware that condoms do not provide protection outside the barrier area; they intended to read more about STDs and learnt something about the subject. Nearly half of the students considered that a course should be offered to all undergraduates. These findings will be of use in defining strategies for prevention and the teaching tool could be used in other learning environments.
\end{abstract}

Key words Sexually transmitted diseases, Education, Higher education
Resumo Doenças sexualmente transmissiveis (DST) são a principal causa global de doença aguda e morte e representam elevado custo socioeconômico. Universitários são altamente expostos. A pesquisa desenvolvida na Unicamp teve como objetivo quantificar e gerar autopercepção do (des)conhecimento sobre as DST, além de avaliar o interesse em uma disciplina sobre o tema. O instrumento de coleta de dados foi o questionário enviado eletronicamente aos graduandos do final de 2011 e aos alunos recém-ingressos em 2012. Responderam o questionário 1.448 veteranos e 371 calouros. Não tinham tido atividade sexual $20 \%$ dos veteranos e $38 \%$ dos calouros. Dos alunos que já haviam tido, 26,9\% não tinham parceria fixa e 28,2\%, mais que duas parcerias/ano. O preservativo foi usado por $99 \%$ dos alunos, mas menos de $20 \%$ deles faziam uso adequado. Cerca de $80 \%$ não sabiam que o preservativo não protege fora da área de barreira; pretendiam ler mais sobre DST e aprenderam algo sobre o assunto. Quase a metade julgou que uma disciplina deveria ser oferecida a todos os graduandos. Estes dados serão úteis para definir estratégias de prevenção e o instrumento didático poderá ser utilizado em outros ambientes de ensino.

Palavras-chave Doenças Sexualmente Transmissíveis, Ensino, Educação superior 


\section{Introdução}

A Lei de Diretrizes e Bases da Educação Nacional (LDB), número 9.394/96, artigo 43, define que o ensino superior estimule a criação cultural, $\mathrm{o}$ desenvolvimento do espírito científico e do pensamento reflexivo. De acordo com o texto, este nível de ensino deve formar, nas diferentes áreas do conhecimento, profissionais aptos a atuar nos diversos setores de trabalho e a participar do desenvolvimento da sociedade. A lei também atribui ao ensino superior a missão de colaborar na formação contínua, incentivar o trabalho de pesquisa e investigação científica; estimular o conhecimento dos problemas do mundo presente, prestar serviços especializados à comunidade $\mathrm{e}$ estabelecer, com esta, uma relação de reciprocidade. Finalmente, o ensino na Educação Superior deve ser bastante abrangente, com a função de educar o cidadão socialmente, independente de sua área de conhecimento ${ }^{1}$.

A LDBEN converge com a preocupação mundial de humanizar o ensino superior, particularmente na educação em saúde. No Brasil, esta prioridade culminou com o Programa Humaniza SUS, uma Política Nacional de Humanização que existe desde 2003 para efetivar os princípios do Sistema Único de Saúde (SUS) nas práticas de atenção e gestão, qualificando a saúde pública e incentivando trocas solidárias entre gestores, trabalhadores e usuários ${ }^{2}$. As instituições formadoras de profissionais da saúde, como as universidades, não podem deixar de participar deste processo, mas é imprescindível que todos os cursos de graduação sejam estimulados a priorizar ações que contribuam para a formação de uma sociedade do conhecimento em que os problemas (e as soluções) sociais sejam assumidos por todos os cidadãos ${ }^{3,4}$.

A LDB, em seu art. 35, identifica o Ensino Médio como período que assegura o desenvolvimento da formação para o amplo exercício da cidadania, portanto, nas duas etapas da educação brasileira (básica e superior), objetiva-se uma educação abrangente aos adolescentes.

No Brasil, a legislação ${ }^{5}$ define adolescentes aqueles que se encontram entre 12 e 18 anos e, segundo a Organização Mundial de Saúde (OMS), são jovens os que se encontram entre 10 e 24 anos $^{6}$.

Nesta faixa etária, as doenças sexualmente transmissíveis (DST) são comuns. Segundo a OMS, elas são a principal causa global de doença aguda, infertilidade, invalidez e morte e promovemgraves consequências psicológicas para milhões de homens, mulheres e crianças ${ }^{2,7}$. Essas enfermidades são subdiagnosticadas e constituem importante causa de morbimortalidade, representando elevado custo socioeconômico em países em desenvolvimento e industrializados ${ }^{8}$. As campanhas preventivas do Ministério da Saúde visam à faixa etária adotada pela $\mathrm{OMS}^{6}$.

As DST são mais prevalentes entre jovens de 14 a 29 anos, e os universitários constituem população altamente exposta a agentes destas doenças, muitas vezes portando-as de forma assintomática ${ }^{7,9,10}$.

Entre as doenças de maior importância clínica estão a gonorreia, a sífilis, a tricomoníase, o cancroide, o herpes genital, as verrugas genitais, as infecções por clamídia, pelo vírus da hepatite B e pelo vírus da imunodeficiência humana, o HIV ${ }^{11}$.

A presença destas infecções aumenta em grande proporção o risco de contrair o HIV. Esta interação poderia explicar $40 \%$ ou mais dos casos de transmissão deste vírus, inclusive na população dos 15 aos 24 anos $^{11,12}$.

É frequente pacientes com o diagnóstico de infecções sexualmente transmissíveis não serem adequadamente investigados, orientados ou mesmo tratados ${ }^{13,14}$.

A sífilis congênita é um marcador da situação da exposição às outras DST, pois seu diagnóstico é feito pela coleta protocolar de sangue no momento do parto assistido. O aumento na incidência da sífilis congênita observado em todas as regiões brasileiras sinaliza o avanço das DST no Brasil (Figura 1) ${ }^{15}$. Aspectos culturais e comportamentais atuais podem estar envolvidos com este crescimento, como a rejeição por seguir regras, o egocentrismo, a transvaloração dos valores, a valorização da tecnologia em detrimento da ciência ${ }^{16}$.

O conhecimento é importante instrumento na prevenção de DST. Estudo realizado entre jovens com mais de 18 anos que frequentavam casas noturnas de Fortaleza confirma esta afirmação. De acordo com a pesquisa, 38\% deles portavam preservativos e destes, $40 \%$ o carregavam inadequadamente na carteira ${ }^{17}$.

Contudo, é necessário ressaltar que não basta o conhecimento sobre a necessidade de usar o preservativo na prevenção destas doenças; é necessário que o indivíduo tenha conhecimento sobre as DST para poder considerar os riscos e as consequências de adquiri-las. Para Paiva et al. ${ }^{18}$, tanto os espaços formais como os não formais propiciam o desenvolvimento da educação. Não é demais repetir que a educação em saúde é um 


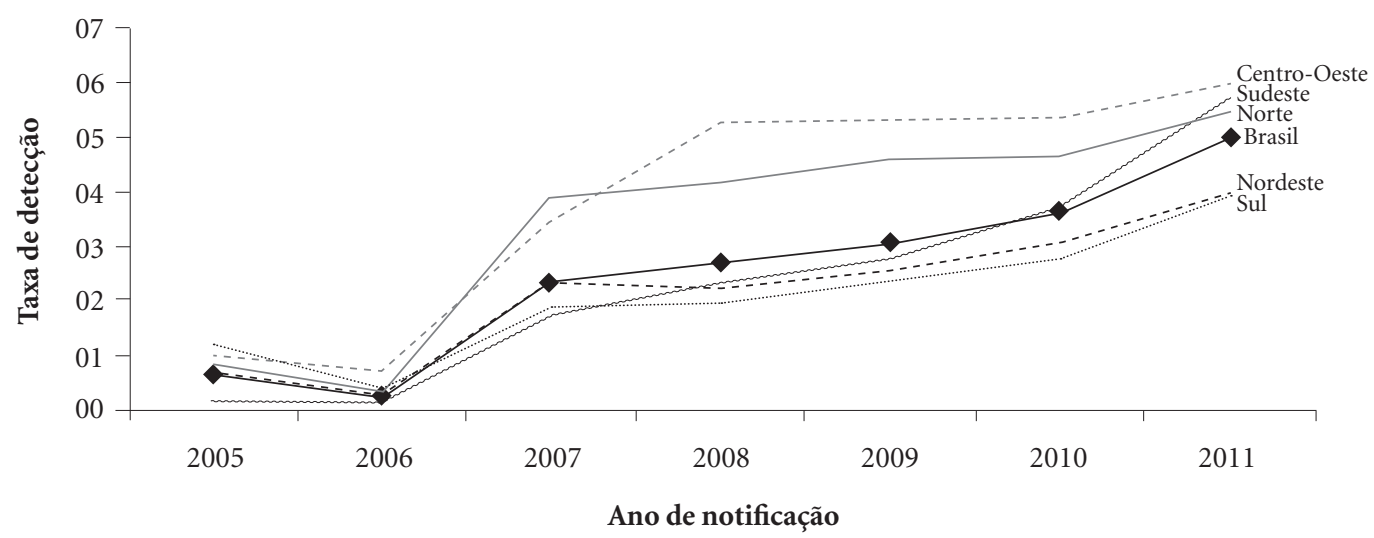

Figura 1. Taxa de incidência de sífilis congênita em menores de 1 ano de idade (por 1.000 nascidos vivos) por região de residência e ano de diagnóstico. Brasil, 2005 a $2011^{10}$.

componente central em sua promoção, no entanto, Do Val ${ }^{19}$ ressalta que "os programas de educação em saúde são construídos, muitas vezes, de forma verticalizada, em que o educador em saúde detém o conhecimento e cria programas de prevenção sem conhecer o público a quem se destina".

Cordeiro $^{20}$ e Temporini ${ }^{21}$ têm se dedicado ao estudo da relação existente entre conhecimentos, atitudes, crenças, comportamentos e valores aliados às variáveis demográficas. No primeiro estudo, realizado com 1.021 estudantes do ensino médio nas escolas públicas estaduais de São Paulo, verificou-se que $37 \%$ conheciam o uso do preservativo, mas $55,5 \%$ tinham dúvidas.

Trajman et al. ${ }^{22}$ documentaram que, entre estudantes do ensino médio do Rio de Janeiro, 94\% conheciam o benefício do uso do preservativo, mas apenas $34 \%$ referiam usá-lo sempre. Não foi observada diferença estatística entre o conhecimento insatisfatório e o uso inconstante do preservativo ${ }^{22}$.

Saldanha et al..$^{23}$ desenvolveram estudo com adolescentes no município de João Pessoa e identificaram fatores de risco para as DST, tais como ausência de preservativo nas relações sexuais e multiplicidade de parceiros, associados e influenciados pelas questões de gênero sociais e históricas.

Estudo com 8.741 adolescentes realizado na Paraíba ${ }^{24}$ originou três categorias que pudessem apontar os determinantes de vulnerabilidade à infecção pelo HIV: a) prática sexual (iniciação se- xual e fatores determinantes); b) prevenção (uso de preservativo e métodos anticoncepcionais); c) vulnerabilidade à aids (percepção de vulnerabilidade e informações). Três anos depois, o mesmo autor realizou estudo com objetivo de verificar os efeitos da aplicação de estratégia de intervenção psicoeducativa na prevenção das DST para adolescentes e concluiu que "a educação e as políticas públicas que priorizem ações de promoção de saúde não podem enfocar apenas no indivíduo, mas considerar seu gênero, história, contexto cultural, social, histórico e suas relações intersubjetivas de trocas e construção do eu, o que possibilita a perspectiva de um sujeito-cidadão"25.

Como informado anteriormente, no Brasil, a LDB fixa as diretrizes e as bases da educação nacional e, acerca do Ensino, elenca seus princípios (art. 30): igualdade de condições para o acessado e permanência em instituição de ensino; liberdade para aprender, ensinar, pesquisar e divulgar a cultura, o pensamento, a arte e o saber; pluralismo de ideias e de concepções pedagógicas, dentre outros. A lei também estabelece que a educação escolar seja composta pela educação básica e pela superior.

As DST têm sido objeto tanto de campanhas governamentais quanto de conteúdos de disciplinas nos ensinos em saúde, médio e superior.

A participação dos profissionais da saúde na disseminação do conhecimento acerca das DST é essencial. Nesse sentido, o termo humanização ganha cada vez mais espaço no âmbito das prá- 
ticas em saúde, sendo possível concordar com Ibañez et al. ${ }^{26}$ quando enfatizam que "a construção de uma política de humanização é uma obra aberta e que estamos conscientes que o percurso que se nos abre é longo e árduo".

O próprio termo humanização é polissêmico e, segundo Diniz ${ }^{27}$, pode apresentar variadas interpretações. Zeni e Cutolo ${ }^{28}$ assim conceituam humanização:

Atitudes menos reducionistas e fragmentárias, respeitando a integralidade que constitui um ser, recusando-se em reduzi-lo a um sistema ou estrutura biológica [...] A capacidade de responder ao sofrimento humano, que, nem sempre, será o sofrimento atribuído a uma doença [...]. Postura de comprometimento - tudo aquilo que se faz a mais, ser colaborativo ao outro, alguém que se 'sabe que pode contar' - e de responsabilização - saber o que tem que fazer, e fazer! Respeitando os que estão a sua volta, tornar-se responsável pelas suas ações e as consequências destas [...] Uma ação transversal, que rompa com fronteiras, não seja associada a um momento específico da ação, e sim, permeie entre todas as ações em saúde [...]. Seja construída sobre a base de trocas de saberes, do diálogo (incluindo os dos pacientes e seus familiares), respeitando e valorizando as necessidades sociais, os desejos e interesses de todos.

É possível concluir que informar e responsabilizar os jovens sobre possíveis consequências do exercício da sua sexualidade é também humanizar essa questão de saúde. Assim, há necessidade de campanhas preventivas entre os universitários no próprio locus onde os estudantes estejam.

Considerando o exposto e a problemática do conhecimento sobre as DST entre os jovens recém-egressos do ensino médio e que ingressaram na graduação, este estudo objetivou avaliar a percepção das DST entre universitários e desenvolver um instrumento didático. Tal instrumento geraria autopercepção do conhecimento/desconhecimento sobre as DST e avaliaria o interesse desses em participar de uma disciplina sobre o tema. Sabe-se que a própria participação do aluno em pesquisas deste tipo proporciona conhecimento sobre o tema e pode despertar o interesse do estudante pelo assunto. Assim, os autores pretendem que a pesquisa seja um instrumento de informação sobre estas infecções, consistindo numa ação preventiva entre os alunos.

Os objetivos desta pesquisa levaram à união de profissionais da área da saúde e da educação, apontando com isso que a questão sobre conhecimento, valores e comportamentos sociocul- turais ultrapassa os limites de área específica. O questionário é "um instrumento que nos colocará em contato com aquele que responde" ${ }^{29}$. Assim, o instrumento da presente pesquisa foi concebido com dupla aplicação: obter dados acerca do conhecimento do tema com os graduandos calouros na Instituição de Ensino, inclusive com ilustrações, e proporcionar o ensino das questões mais relevantes no formato de feedback às respostas dadas.

\section{Sujeitos e Métodos}

Trata-se de pesquisa de corte transversal do tipo inquérito CAP (conhecimento, atitude e prática). $\mathrm{O}$ instrumento de ensino foi um questionário, construído após a realização de um pré-teste com dez indivíduos, enviado online a todos os graduandos da Unicamp por meio de convite feito pela Diretoria Acadêmica, no final do ano letivo de 2011 e em março de 2012, aos alunos recém-ingressos, utilizando a ferramenta de pesquisa online denominada EnqueteFacil ${ }^{\circ}$.

O questionário abordava os seguintes aspectos:

a) caracterização dos voluntários como sexo, idade, curso e hábitos sexuais;

b) informações sobre DST e sua prevenção;

c) associação de DST a imagens;

d) impressão dos sujeitos sobre a relevância do tema;

e) interesse dos alunos na leitura dos comentários sobre cada questão e sobre as infecções de transmissão sexual.

Ao final das perguntas, havia comentários informativos sobre as mesmas que poderiam ser acessados. O convite encaminhado foi aprovado pelo Comitê de Ética em Pesquisa e acompanhado do termo de consentimento livre e esclarecido. Neste termo, os graduandos foram informados dos aspectos éticos da pesquisa e de sua participação voluntária e anônima. Ao acessar o questionário, o aluno concordava com sua participação e os dados de respostas eram armazenados online, possibilitando análises estatísticas em tempo real. Os dados foram exportados para o software SPSS 16.0 (SPSS Inc., Chicago, IL, USA) e processados em tabelas contendo as frequências relativas e absolutas. Para comparar proporções, utilizaram-se os testes qui-quadrado, exato de Fisher, para as tabelas 2x2, e exato de Fisher-Freeman-Halton, para as tabelas maiores. Em todos os casos, adotou-se o nível de significância de 5\%. 


\section{Resultados}

Foram enviados convites aos 16.787 graduandos matriculados na Unicamp em 2011, sendo que 1.448 responderam o questionário. Dados sobre o conhecimento das DST, sua forma de prevenção e sobre a avaliação do instrumento didático incluído no questionário foram comparados com as respostas obtidas de 371 dentre os 3.320 alunos que ingressaram em 2012.

Quanto à faixa etária, 95,9\% estavam entre 16 e 29 anos e, quanto ao gênero, observou-se que $50 \%$ eram de cada sexo, embora esta igualdade na proporção não tenha sido intencionada.

A Unicamp encontra-se dividida em quatro áreas de formação e, na pesquisa, houve representatividade de todas as áreas e de todos os semestres letivos. Na Tabela 1, observa-se que houve proporcionalidade entre as vagas de cada área e o número de respondentes.

Dentre os graduandos do final de 2011, 20\% informaram que não haviam tido atividades sexuais (21,3\% dos homens, $18,7 \%$ das mulheres). Entre os calouros de 2012, esta porcentagem foi de $38 \%$, e outros $5,7 \%$ haviam tido atividade após se tornarem universitários. Dos alunos de 2011, 51\% iniciaram a atividade sexual antes de ser universitários (48,7\% das mulheres e 53,3\% dos homens).

Sabe-se que quanto mais parceiros, maior a vulnerabilidade $^{30}$, e os resultados apontaram que dos alunos que já haviam tido atividade sexual, um em cada quatro $(26,9 \%)$ referia não ter parceria fixa e $28,2 \%$ referiam ter tido mais de duas parcerias sexuais por ano. Dentre os $73,1 \%$ dos que referiam parceria fixa, $16,8 \%$ informaram atividade há até seis meses, 25,1\%, há até 12 meses, e $32,4 \%$ informaram manter a mesma parceria há mais de dois anos.

Quanto à idade de iniciação sexual, 52,8\% dos alunos iniciaram a atividade sexual entre os 16 e 18 anos e 11,6\% deles, entre 13 e 15 anos. Até 18 anos, $65,3 \%$ dos homens e $65,8 \%$ das mulheres haviam iniciado a atividade sexual.

Houve diferença estatisticamente significante entre a idade de iniciação sexual dos veteranos (final de 2011) e dos calouros, mostrando maior precocidade dos alunos que ingressaram em 2012 (Tabelas 2 e 3 ).

A bissexualidade foi informada por $9 \%$ dos veteranos, enquanto $5,8 \%$ dos homens e $1,1 \%$ das mulheres informaram a homossexualidade. Em 2012, a bissexualidade foi informada por $10,2 \%$ dos alunos, a homossexualidade, por $8 \%$ dos homens e $1,3 \%$ das mulheres.
Tabela 1. Proporção de vagas oferecidas pela Unicamp nas grandes áreas e a proporção por área dos respondentes de 2011 e 2012 ( $\mathrm{p}>0,05)$.

\begin{tabular}{lccc}
\hline \multicolumn{1}{c}{ Área } & $\begin{array}{c}\text { Unicamp } \\
(\%)\end{array}$ & $\begin{array}{c}\mathbf{2 0 1 1} \\
(\%)\end{array}$ & $\begin{array}{c}\mathbf{2 0 1 2} \\
(\%)\end{array}$ \\
\hline Artes & $175 / 3320$ & $69 / 1448$ & $21 / 371$ \\
& $(5,3)$ & $(4,8)$ & $(5,7)$ \\
Ciências Biológicas & $610 / 3320$ & $263 / 1448$ & $75 / 371$ \\
& $(18,4)$ & $(18,2)$ & $(20,3)$ \\
Ciências Exatas & $1760 / 3320$ & $859 / 1448$ & $191 / 371$ \\
& $(53,0)$ & $(59,4)$ & $(51,8)$ \\
Ciências Humanas & $775 / 3320$ & $255 / 1448$ & $82 / 371$ \\
& $(23,3)$ & $(17,6)$ & $(22,2)$ \\
\hline
\end{tabular}

Tabela 2. Idade de início da atividade sexual dos alunos do sexo masculino de 2011 e 2012 (p<0,05).

\begin{tabular}{ccc}
\hline Idade & $\begin{array}{c}\mathbf{2 0 1 1} \\
(\%)\end{array}$ & $\begin{array}{c}\mathbf{2 0 1 2} \\
(\%)\end{array}$ \\
\hline $13-15$ & $66 / 564$ & $17 / 105$ \\
& $(11,7)$ & $(16,2)$ \\
$16-18$ & $291 / 564$ & $63 / 105$ \\
& $(51,6)$ & $(60,0)$ \\
$19-21$ & $165 / 564$ & $17 / 105$ \\
& $(29,3)$ & $(16,2)$ \\
\hline
\end{tabular}

Tabela 3. Idade de início da atividade sexual dos alunos do sexo feminino de 2011 e 2012 (p < 0,05).

\begin{tabular}{ccc}
\hline Idade & $\begin{array}{c}\mathbf{2 0 1 1} \\
(\%)\end{array}$ & $\begin{array}{c}\mathbf{2 0 1 2} \\
(\%)\end{array}$ \\
\hline $13-15$ & $67 / 578$ & $25 / 122$ \\
& $(11,6)$ & $(20,5)$ \\
$16-18$ & $312 / 578$ & $73 / 122$ \\
& $(54,0)$ & $(59,8)$ \\
$19-21$ & $169 / 578$ & $18 / 122$ \\
& $(29,2)$ & $(14,8)$ \\
\hline
\end{tabular}

Sobre o conhecimento das formas de prevenção, 99\% dentre os alunos que haviam tido relações sexuais referiram já ter usado o preservativo. O uso constante do preservativo foi apontado por $30,5 \%$ daqueles que haviam tido atividade sexual, mas menos de $20 \%$ deles faziam uso adequado deste método de prevenção.

Foi perguntado aos alunos se já tinham sido diagnosticados com uma DST, sendo obtidas as seguintes respostas: $8,6 \%$ dos alunos sabiam ter 
tido uma DST e 8,4\% não tinham segurança sobre isso. Quase 5\% informaram ter tido relação com alguém que havia tido uma DST. A quantidade dos que negaram relação com alguém que teve uma DST foi equivalente a 56,5\% dos respondentes. Por outro lado, 46,9\% dos alunos conheciam alguém que teve uma DST e 14,3\% não souberam responder essa pergunta.

Sobre o slogan da campanha do governo de 2008: Faça o que quiser, mas faça com camisinha, $43 \%$ dos graduandos apreenderam que estariam $100 \%$ seguros se usassem preservativos e/ou que usar preservativos garantiria que não adquiririam DST.

Foram feitas afirmações sobre os métodos de prevenção das DST extraídas da OMS. Apenas $11,5 \%$ dos alunos concordaram que todas as afirmações eram corretas.

Acerca das doenças, foram apresentadas imagens de pacientes com DST. Estes dados estão resumidos na Tabela 4.

Entre os alunos, $81 \%$ reconheceram ter dúvidas sobre o tema, $69,7 \%$ referiram ter aprendido algo ao responder o questionário e $87,3 \%$ se dispuseram a ler os comentários sobre o instrumento da pesquisa. Quase a metade dos alunos julgou que uma disciplina obrigatória deveria ser oferecida a todos. Dos que mencionaram interesse em fazer a disciplina, 48,2\% pensam que ela deveria ser obrigatória, 49\% consideram que deveria ser optativa e 56,7\% avaliam que poderia ser desenvolvida como um curso a distância. (Tabela 4)

Dentre os alunos, mais de 95\% que responderam as perguntas referentes aos comentários afirmaram ter aprendido algo, e 81,4\% referiram que pretendiam ler mais sobre o assunto. A Tabela 4 compara as porcentagens de repostas obtidas entre alunos há pelo menos um ano na faculdade com as dos calouros. Não houve diferença estatística significante entre elas $(\mathrm{p}>0,05)$.

\section{Discussão}

O ensino na Educação Superior no Brasil deve ser bastante abrangente, estimulando o conhecimento dos problemas do mundo e capacitando futuros profissionais como cidadãos aptos a participar do desenvolvimento da sociedade. Esperase que o cidadão-graduando seja educado socialmente, independente da área de conhecimento de sua formação ${ }^{1}$. Almeja-se, assim, humanizar o ensino ${ }^{3,4}$.

Como foi dito, as DST são mais prevalentes entre jovens de 14 a 29 anos, e os universitários são uma população altamente exposta a contrair os agentes destas doenças, muitas vezes portando-os de forma assintomática ${ }^{7,10,31}$. Quase a totalidade dos respondentes, 95,8\%, encontravam-se na faixa etária entre 16-29 anos. Contudo, 63,8\% dos veteranos que já haviam iniciado a atividade sexual o fizeram antes de ser universitários, mostrando que campanhas informativas devem, de fato, ser iniciadas mais precocemente. Outra razão que justifica ações mais precoces é a de que houve diferença estatisticamente significante entre a quantidade de alunos que haviam iniciado a atividade sexual entre 13 e 15 anos, informada pelos recém-ingressos de 2012 . Ou seja, a pesquisa demonstra que os jovens estão iniciando sua vida sexual cada vez mais cedo.

Não haviam iniciado a atividade sexual quando entraram na faculdade $49 \%$ dos respondentes de 2011 e 43,7\% de 2012. Isto significa que grande parte dos ingressantes poderá se beneficiar de precoce informação sobre as infecções de transmissão sexual nas universidades, bem como ser vacinada, caso ainda não tenham sido, para a hepatite B e HPV.

Segundo dados do Boletim Epidemiológico do governo brasileiro, o resultado positivo para o HIV está relacionado, principalmente, ao número de parcerias (quanto mais parceiros, maior a vulnerabilidade), coinfecção com outras DST e relações homossexuais. Em relação à forma de transmissão entre os maiores de 13 anos de idade, prevalece a sexual. Nas mulheres, 94,9\% dos casos registrados em 2009 decorreram de relações heterossexuais com pessoas infectadas pelo HIV. Entre os homens, 42,9\% foram contaminados por relações heterossexuais, 19,7\%, homossexuais e $7,8 \%$, bissexuais. $O$ restante foi por transmissão sanguínea e vertical ${ }^{30}$.

Entre os alunos que já haviam tido relações sexuais no momento da pesquisa, $28,2 \%$ referiam ter mais que duas parcerias por ano. Quanto ao número de parcerias sexuais ao longo de um ano, os alunos responderam que: $1 \%$ referia ter de 13 a 20 parcerias sexuais por ano e 1\%, mais de 20 parcerias sexuais. Isto pode justificar casos de cancro mole observados entre estes universitários, pois, para que o agente do cancro mole se mantenha em uma população, é necessário que uma porcentagem desta tenha elevado número de parcerias sexuais ${ }^{32}$.

O preservativo masculino foi usado por $99 \%$ dos alunos que referiram ter tido relações sexuais, mas $69,5 \%$ deles não o utilizaram em todas as relações. Como pouco mais de $1 \%$ dos alunos nunca usou preservativo nas suas relações, mais 
Tabela 4. Respostas dos alunos do final de 2011 e do início de 2012(p > 0,05).

\begin{tabular}{|c|c|c|}
\hline & $\begin{array}{c}\text { Veteranos } \\
(\%)\end{array}$ & $\begin{array}{c}\text { Calouros } \\
(\%)\end{array}$ \\
\hline Não identificaram lesões por HPV & $\begin{array}{c}909 / 1203 \\
(75,6)\end{array}$ & $\begin{array}{c}225 / 312 \\
(72,1)\end{array}$ \\
\hline Consideraram que o preservativo protege mesmo fora da área de barreira & $\begin{array}{c}926 / 1202 \\
(77,1)\end{array}$ & $\begin{array}{c}247 / 311 \\
(79,5)\end{array}$ \\
\hline Não identificaram lesões de herpes simples & $\begin{array}{c}1000 / 1201 \\
(83,3)\end{array}$ & $\begin{array}{c}269 / 311 \\
(86,5)\end{array}$ \\
\hline Não concordaram que uma DST aumenta 10 vezes o risco de infecção pelo HIV & $\begin{array}{c}884 / 1200 \\
(73,7)\end{array}$ & $\begin{array}{c}216 / 310 \\
(69,7)\end{array}$ \\
\hline Não consideraram a hepatite B como uma DST & $\begin{array}{c}325 / 1200 \\
(27,1)\end{array}$ & $\begin{array}{l}91 / 310 \\
(29,4)\end{array}$ \\
\hline Não consideraram o câncer de colo uterino como DST & $\begin{array}{c}795 / 1200 \\
(66,3)\end{array}$ & $\begin{array}{c}209 / 310 \\
(67,4)\end{array}$ \\
\hline Não associaram o condiloma ao HPV & $\begin{array}{c}739 / 1164 \\
(63,5)\end{array}$ & $\begin{array}{c}189 / 293 \\
(64,4)\end{array}$ \\
\hline Consideraram lesões causadas pelo HPV parecidas com uma "pinta" & $\begin{array}{c}918 / 1163 \\
(78,9)\end{array}$ & $\begin{array}{c}225 / 293 \\
(76,8)\end{array}$ \\
\hline Não sabiam que não há cura para a infecção pelo herpes vírus & $\begin{array}{c}921 / 1162 \\
(79,3)\end{array}$ & $\begin{array}{c}234 / 293 \\
(79,9)\end{array}$ \\
\hline Afirmaram ter dúvidas sobre DST & $\begin{array}{c}942 / 1163 \\
(81,0)\end{array}$ & $\begin{array}{c}232 / 293 \\
(79,2)\end{array}$ \\
\hline Consideraram pertinente uma disciplina obrigatória sobre o tema & $\begin{array}{c}560 / 1163 \\
(48,2)\end{array}$ & $\begin{array}{c}152 / 293 \\
(51,9)\end{array}$ \\
\hline Cursariam uma disciplina optativa sobre o tema & $\begin{array}{c}570 / 1163 \\
(49,0)\end{array}$ & $\begin{array}{c}147 / 293 \\
(50,2)\end{array}$ \\
\hline Cursariam uma disciplina à distância sobre o tema & $\begin{array}{c}659 / 1163 \\
(56,7)\end{array}$ & $\begin{array}{c}165 / 293 \\
(56,3)\end{array}$ \\
\hline Afirmaram ter aprendido algo sobre o tema & $\begin{array}{c}811 / 1163 \\
(69,7)\end{array}$ & $\begin{array}{c}198 / 293 \\
(67,6)\end{array}$ \\
\hline Pretendiam ler os comentários sobre as perguntas & $\begin{array}{c}1005 / 1151 \\
(87,3)\end{array}$ & $\begin{array}{c}253 / 287 \\
(88,2)\end{array}$ \\
\hline Aprenderam sobre dados de identificação & $\begin{array}{c}750 / 820 \\
(91,5)\end{array}$ & $\begin{array}{c}195 / 213 \\
(91,5)\end{array}$ \\
\hline Aprenderam sobre conhecimento das DST e prevenção & $\begin{array}{c}588 / 793 \\
(74,1)\end{array}$ & $\begin{array}{c}162 / 208 \\
(77,9)\end{array}$ \\
\hline Aprenderam sobre o uso correto do preservativo masculino & $\begin{array}{c}706 / 794 \\
(88,9)\end{array}$ & $\begin{array}{c}186 / 207 \\
(89,9)\end{array}$ \\
\hline Aprenderam sobre o slogan "Faça o que quiser, mas faça com camisinha" & $\begin{array}{c}637 / 762 \\
(83,6)\end{array}$ & $\begin{array}{c}177 / 204 \\
(86,8)\end{array}$ \\
\hline Aprenderam sobre a ação de barreira dos preservativos & $\begin{array}{c}712 / 793 \\
(89,8)\end{array}$ & $\begin{array}{c}183 / 204 \\
(89,7)\end{array}$ \\
\hline Aprenderam sobre lesões causadas pelo HPV & $\begin{array}{c}759 / 792 \\
(95,8)\end{array}$ & $\begin{array}{c}198 / 206 \\
(96,1)\end{array}$ \\
\hline Aprenderam sobre herpes simples & $\begin{array}{c}743 / 806 \\
(92,2)\end{array}$ & $\begin{array}{c}194 / 205 \\
(94,6)\end{array}$ \\
\hline Aprenderam sobre hepatite B e o câncer de colo uterino & $\begin{array}{c}652 / 796 \\
(81,9)\end{array}$ & $\begin{array}{c}176 / 205 \\
(85,9)\end{array}$ \\
\hline Pretendiam estudar mais sobre o tema & $\begin{array}{c}643 / 790 \\
(81,4)\end{array}$ & $\begin{array}{c}157 / 203 \\
(77,3)\end{array}$ \\
\hline
\end{tabular}

de $70 \%$ dos graduandos da Unicamp que tiveram atividade sexual deixaram de usar o preservativo em algumas relações sexuais. Considerando tam- bém as respostas erradas ou incompletas sobre forma correta do uso do preservativo, menos de $20 \%$ dos graduandos da universidade usufruem 
da proteção que o preservativo pode oferecer. Embora a proteção que o preservativo ofereça quando usado corretamente e de forma constante não seja completamente conhecida, considerase que possa proteger $80 \%-95 \%$ da transmissão do HIV, $70 \%$ da transmissão do HPV e 50\% na transmissão do herpes simples. Ele é certamente eficaz em reduzir também o risco de transmissão das uretrites e da sífilis ${ }^{33}$. Em um estudo de revisão, a efetividade da proteção na transmissão do HIV entre casais sorodiscordantes que sempre usavam o preservativo foi considerada de $80 \%{ }^{34}$. Os mesmos autores haviam mostrado, revisando a literatura, que não havia diferença entre não usar o preservativo ou usá-lo algumas vezes ${ }^{35}$. Apesar de a proteção do preservativo não atingir $100 \%$, mesmo quando usado de forma adequada, é consensual que seu uso correto deve ser estimulado em todas as relações sexuais.

O conhecimento é importante na prevenção destas doenças, mas não basta estar ciente da necessidade de usar o preservativo. Como foi mencionado, no estudo brasileiro de Carvalho et al., 94\% dos estudantes de ensino médio avaliados conheciam o benefício do uso do preservativo, mas apenas $34 \%$ referiam usá-lo sempre. Não foi observada diferença estatística entre o conhecimento insatisfatório e o uso inconstante do preservativo $^{17}$. No presente estudo, observou-se que $99 \%$ dos graduandos sexualmente ativos já haviam usado preservativo em suas relações, mas menos de $20 \%$ deles usaram sempre ou tinham conhecimento suficiente para tê-lo usado adequadamente. A informação nesta área deve ser a mais exata e completa possível, de forma que o indivíduo possa ter consciência dos riscos aos quais se expõe e que podem também afetar terceiros na sua prática sexual.

Contudo, informações baseadas em trabalhos científicos, devem ser transmitidas cuidadosamente. Cassell et al. ${ }^{36}$ encontraram na Inglaterra um aumento significativo no uso de preservativos quando compararam os dados obtidos dez anos antes, particularmente entre jovens de 1624 anos. Observaram também um aumento no número de parcerias sexuais e no índice de parcerias concomitantes e, com isto, um aumento na incidência das DST. Eles discutem que o preservativo só pode reduzir o aumento potencial da transmissão, se for associado ao uso correto e consistente deste método. Reforçam também que esta faixa etária deve ser alvo de intervenções intensas e específicas de saúde sexual ${ }^{36}$.

As campanhas de prevenção devem ser cuidadosamente pensadas. Exemplifica esta necessida- de a campanha do governo brasileiro, veiculada em 2008: Faça o que quiser, mas faça com camisinha. Dentre os respondentes, $43 \%$ dos graduandos apreenderam que estariam 100\% seguros se usassem preservativos nas suas relações sexuais e/ ou que usar preservativo garantia que não iriam adquirir DST. Outros estudos são necessários para documentar se essa informação equivocada levou a uma maior exposição de risco desses indivíduos.

Cerca de $80 \%$ dos alunos não sabiam que o preservativo não protege contra a transmissão de lesões cutâneas fora da área onde faz barreira. Além disso, 83,3\% deles reconheceram não saber identificar lesões de herpes simples, a DST mais prevalente com as infecções pelo HPV. Quando identificadas lesões discretas da infecção pelo HPV, $79,3 \%$ dos alunos disseram que elas poderiam ser confundidas com lesões comuns como "pintas". O mesmo percentual de alunos não sabia que o herpes simples não tem tratamento que garanta cura e por isso as lesões podem recorrer periodicamente durante muitos anos. Além disso, $73,7 \%$ dos alunos não sabiam que quem tem uma DST tem dez vezes mais chance de ter contraído ${ }^{8}$ também o HIV e 66,3\% deles, que o câncer de colo uterino, o segundo mais prevalente entre as mulheres brasileiras e uma das causas mais frequentes de óbito na população feminina em todo o mundo, poder ser considerado uma DST, pois em 99,7\% dos casos, o HPV pode ser identificado no tecido tumoral ${ }^{31,37}$. Isso mostra que o conhecimento sobre a necessidade de usar preservativo não é acompanhado de ciência sobre a consequência do uso inadequado entre estes alunos.

Chama atenção a alta porcentagem dos alunos que discordaram das afirmações da Organização Mundial da Saúde como efetivas na prevenção das DST (88,5\%). Entre as informações com as quais não concordaram estão a existência de vacinas que podem ajudar a proteger contra DST, a saber, hepatite B e HPV, a efetividade do tratamento de outras DST na prevenção da transmissão do HIV, a efetividade da monogamia por tempo prolongado entre parceiros não infectados como forma de prevenção e a necessidade de avaliação médica das parcerias sexuais de pessoas que tenham infecção sexualmente transmissível.

A quantidade dos alunos que negaram ter tido relações com alguém que teve uma DST foi $56,5 \%$, porém, ninguém que teve atividade sexual pode garantir que não se expôs às DST, já que em relação à sexualidade, a única certeza que se pode ter é referente a si próprio e não à parceria 
sexual. Pode-se confiar/acreditar na outra pessoa, mas não há como ter garantias. Esta é a justificativa para se orientar o uso do preservativo em todas as relações sexuais.

Mais de 70\% dos alunos, inclusive os da graduação em Medicina, reconheceram ter dúvida sobre o tema, se dispuseram a ler os comentários e afirmaram que pretendiam ler mais sobre as DST após terem participado da pesquisa. Entre os que participaram até o final da pesquisa, mais de 95\% aprenderam algo sobre estas infecções.

A pesquisa permitiu também identificar subpopulações de maior risco a serem priorizadas em futuras campanhas de prevenção (informação não apresentada).

A efetividade do conhecimento adquirido de mudar o comportamento dos alunos de forma a diminuir a exposição de risco não poderá ser avaliada com este instrumento de pesquisa. Estudos futuros deverão complementar a informação aqui adquirida.

\section{Conclusão}

A pesquisa permitiu constatar que os alunos da Unicamp conheciam pouco sobre as DST e seus agentes. $\mathrm{O}$ tema foi de interesse geral e não ape- nas dos alunos da área da saúde. Mais da metade dos alunos cursaria uma disciplina $(56,7 \%)$ sobre o tema e estudaria mais sobre questões abordadas no questionário $(81,4 \%)$. O questionário com seus comentários foi, além de um instrumento de pesquisa, um material didático, já que $87,3 \%$ dos alunos se interessaram em ler os comentários e mais de $95 \%$ dos respondentes admitiram ter aprendido algo ao final da pesquisa. Este conhecimento será útil em definir estratégias de prevenção não apenas nesta universidade, e o material didático poderá ser utilizado em outros ambientes de ensino ${ }^{38,39}$.

\section{Colaboradores}

EL Castro, TA Caldas, AM Morcillo, EMA Pereira e PENF Velho contribuíram substancialmente para a concepção e planejamento, ou análise e interpretação dos dados; na elaboração do rascunho ou na revisão crítica do conteúdo e todos participaram da aprovação da versão final do manuscrito.

\section{Referências}

1. Brasil. Lei n. 9.394 de 20 de dezembro, 1996. LDB: Lei de Diretrizes e Bases da Educação Nacional. Diário Oficial da União 1996; $20 \mathrm{dez}$.

2. Brasil. Ministério da Saúde (MS). Saude.gov.br [página na internet]. [acessado 2013 maio 5]. Disponível em: http://portal.saude.gov.br/portal/saude/cidadao/area. cfm?id_area $=1342$

3. Rego S, Gomes AP, Batista RS. Bioética e humanização como temas transversais na formação médica. Rev. bras. educ. med. 2008; 32(4):482-491.

4. Esteves M. Para a excelência pedagógica do ensino superior. Rev Cienc Educ 2008; 7:101-110.

5. Brasil. Lei n. 8.069 de 13 de julho, 1990. Decretos. Dispõe sobre o Estatuto da Criança e do Adolescente e dá outras providências. Diário Oficial da União 1990; 13 jul.

6. Brasil. Ministério da Saúde (MS). Departamento de DST, Aids e Hepatites Virais. Juventudes e Participação Adolescentes e Jovens para a educação entre pares: Saúde e prevenção nas escolas. Brasília: MS; 2010.
7. World Health Organization (WHO). Sexually transmitted infections. [página na internet]. [acessado 2013 maio 5]. Disponível em: http://www.euro.who.int/en/ what-we-do/health-topics/communicable-diseases/sexually-transmitted-infections.

8. Wu JJ, Huang DB, Pang KR, Tyring SK. Selected sexually transmitted diseases and their relationship to HIV. Clin Dermatol 2004; 22(6):499-508.

9. Brasil. Ministério da Saúde (MS). Secretaria de Vigilância em Saúde. Programa Nacional de DST e Aids. Manual de Controle das Doenças Sexualmente Transmissíveis. 4a ed. Brasília: MS; 2005. Vol. nº 68.

10. Belda Júnior W. Doenças Sexualmente Transmissíveis. São Paulo: Atheneu; 1999.

11. World Health Organization (WHO). Global strategy for the prevention and control of sexually transmitted infections: 2006-2015. [página na internet]. [acessado 2012 fev 22]. Disponível em: http://whqlibdoc.who.int/ publications/2007/9789241563475_eng.pdf 
12. Organização Mundial da Saúde (OMS). Los jóvenes y los riesgos sanitários. 64a Asamblea Mundial De La Salud. Punto 13.16 del ordendel día provisional. 2010.

13. Lima LHM, Gurgel MFC, Moreira-Silva SF. Avaliação da sífilis congênita no estado do Espírito Santo. DST J Bras doenças sex trans 2006; 18(2):113-116.

14. Santos Júnior A, Andrade MGG, Magalhães RF, Moraes AM, Velho PENF. Sorologia para sífilis: os médicos estão capacitados a interpretá-la? An Bras Dermatol 2007; 82(2):183-185.

15. Brasil. Ministério da Saúde (MS). Secretaria de Vigilância em Saúde. Departamento de DST, Aids e Hepatites. Boletim Epidemiológico Sífilis. Brasília: MS; 2012. Ano I 1:12.

16. Forman P. (Re)cognizing postmodernity: helps for historians of science especially. Ber Wiss 2010; 33:157-175.

17. Carvalho ALS, Bezerra SdJdS, Leitão NMA,Joça MT, Pinheiro AKB. Porte, acondicionamento e utilização de preservativo masculino entre jovens de Fortaleza: um estudo descritivo. Online Braz J Nurs 2007; 6(0).

18. Paiva V, Ayres JR, Buchalla CM. Vulnerabilidade e Direitos Humanos - Prevenção e Promoção da Saúde - Livro I - Da Doença à Cidadania. Curitiba - Brasil: Juruá; 2012.

19. Do Val LF. Estudo dos fatores relacionados à AIDS entre os estudantes do ensino médio [dissertação]. São Paulo: Universidade de São Paulo; 2001.

20. Cordeiro R. Conhecimentos, crenças, opiniões e conduta em relação à AIDS de estudantes do segundo grau de escolas estaduais do município de São Paulo [tese]. São Paulo: Universidade de São Paulo; 1993.

21. Temporini E. Prevenção da AIDS: percepção e conduta sexual de estudantes universitários no estado de São Paulo [tese]. São Paulo: Universidade de São Paulo; 1995.

22. Trajman A, Belo M, Teixeira EG, Dantas VCS, Salomão FM, Cunha AJLA. Conhecimento sobre DST/AIDS e comportamento sexual entre estudantes do ensino médio no Rio de Janeiro, Brasil. Cad Saude Publica 2003; 19(1):127-133.

23. Saldanha AAW, Carvalho EAB, Diniz RF, Freitas ES, Félix SMF, Silva EAA. Comportamento sexual e vulnerabilidade à Aids: um estudo descritivo com perspectiva de práticas de prevenção. DST - J bras Doenças Sex Transm 2008; 20(1):36-44.

24. Ribeiro KCS. Adolescência e Sexualidade: Vulnerabilidade às DSTs, HIV/Aids e a gravidez em adolescentes paraibanos [dissertação]. João Pessoa: Universidade Federal da Paraíba; 2010.

25. Ribeiro KCS. Intervenção psicoeducativa dirigida à prevenção de DSTS e a gravidez não planejada para adolescentes jovens [tese]. João Pessoa: Universidade Federal da Paraíba; 2013.

26. Ibañez N, Elias PEM, Seixas PHDA. Política e gestão pública em saúde. São Paulo: Hucitec; 2011.

27. Diniz S. Gênero, saúde materna e o paradoxo perinatal. Rev Bras Crescimento Desenvolv Hum 2009; 19(2):313326.
28. Zeni P, Cutolo L. Abordagem da humanização na formação acadêmica dos cursos de graduação da área da saúde da Unochapecó - Avaliação dos Planos Pedagógicos de cursos. Rev Saúde Transf Soc 2011; 2(3):88-95.

29. Freitas ALP. A avaliação da confiabilidade de questionários: uma análise utilizando o coeficiente alfa de Cronbach. In: XII SIMPEP. Bauru - São Paulo. 2005.

30. Brasil. Ministério da Saúde (MS). Secretaria de Vigilância em Saúde. Departamento de DST, Aids e Hepatites. Boletim Epidemiológico Aids e DST. Brasília: MS; 2010. Ano VII 1:53.

31. Burd EM. Human papillomavirus and cervical cancer. Clin Microbiol Rev 2003; 16(1):1-17.

32. Bong CT, Bauer ME, Spinola SM. Haemophilus ducreyi: clinical features, epidemiology, and prospects for disease control. Microbes Infect 2002; 4(11):1141-1148.

33. Mindel A, Sawleshwarkar S. Condoms for sexually transmissible infection prevention: politics versus science. Sex Health 2008; 5(1):1-8.

34. Weller S, Davis K. Condom effectiveness in reducing heterosexual HIV transmission. Cochrane Database Syst Rev 2002; (1):CD003255.

35. Davis KR, Weller SC. The effectiveness of condoms in reducing heterosexual transmission of HIV. Fam Plann Perspect 1999; 31(6):272-279.

36. Cassell JA, Mercer CH, Imrie J,Copas AJ, Johnson AM. Who uses condoms with whom? Evidence from national probability sample surveys. Sex Transm Infect 2006; 82(6):467-473.

37. Wolschick NM, Consolaro MEL, Suzuki LE, Boer CG. Câncer do colo do útero: tecnologias emergentes no diagnóstico, tratamento e prevenção da doença. $R B A C$ 2007; 39(2):123-129.

38. Bezerra EO, Chaves ACP, Pereira MLD, Melo FRG. Análise da vulnerabilidade sexual de estudantes universitários ao HIV/AIDS. Rev Rene 2012; 13(5):1121-1131.

39. Panobianco MS, Lima ADF, Oliveira ISB, Gozzo TO. O conhecimento sobre o HPV entre adolescentes estudantes de graduação em enfermagem. Texto \& Contexto - Enfermagem 2013; 22(1):201-207.

Artigo apresentado em 21/05/2014

Aprovado em 31/08/2015

Versão final apresentada em 02/09/2015 